\title{
EVALUASI KELENGKAPAN PERALATAN \\ PRAKTIK INSTALASI TENAGA LISTRIK SMK (Studi Kasus di SMK Taruna Bangsa Bekasi)
}

\author{
${ }^{1}$ Ahmad Ramadhan, ${ }^{2}$ Putra, Soeprijanto, ${ }^{3}$ Massus Subekti. \\ 1,2,3 Pendidikan Teknik Elektro, Fakultas Teknik, Universitas Negeri Jakarta \\ 1,2,3 Email : ramadhanputra876@gmail.com ; soeprijanto@unj.ac.id ; masus@unj.ac.id
}

\begin{abstract}
This research aims to evaluate the completeness level of equipments standard of engineering elevtrical power's installation in Taruna Bangsa Vocational High School, which was ruled in the Ministry of Education's rules No. 12019 and The National Standardization Agency of Indonesia No. 1103-P2-18/19 about the Verification Instruments of Vocational High School, The Organizer of Vocational Practice Exam 2018/2019.This is an evaluative research using a quantitative descriptive approach. The evaluative model used was a discrepancy evaluation model, which was developed by M. Provus. The variable in this research is the equipment of electricity power's installation practice in Taruna Bangsa Vocational High School Bekasi. The methods of collecting the data were three types: observation method, documentation, and interviews. The instrument used was collecting the data using observation paper and list of matched documentation. The analysis technique used in this research is rating scale. The result shows that the reaching of equipment of elecrical power installation practice in Taruna Bangsa Vocational High School Bekasi in academic year of 2018/2019 was categorized as complete with the $89,36 \%$. percentages. The completeness was reviewed from the equipments in practice room as complete (88.5\%), the equipments of learning media room is complete (100\%), the main equipment of practice is complete (93\%), and for the main substance of practice room is complete (88.2\%), also for the equipment support is compelete (77.1\%).
\end{abstract}

Key Words: Evaluation, Practice Equipments, Completeness, Elecrical Power Installation

\begin{abstract}
Abstrak
Penelitian ini bertujuan mengevaluasi tingkat kelengkapan standar peralatan praktik teknik instalasi tenaga listrik di SMK Taruna Bangsa Bekasi yang diatur dalam Permendiknas No. 1 tahun 2019 dan Badan Standar Nasional Pendidikan No. 1103-P2-18/19 mengenai Instrumen Verifikasi SMK Tentang Penyelenggara Ujian Praktik Kejuruan Tahun 2018/2019. Penelitian ini merupakan penelitian evaluatif dengan menggunakan pendekatan deskriptif kuantitatif. Model evaluasi yang digunakan adalah model evaluasi kesenjangan (discrepancy evaluation model) yang dikembangkan oleh M. Provus. Variabel penelitian ini adalah peralatan praktik teknik instalasi tenaga listrik di SMK Taruna Bangsa Bekasi. Metode pengumpulan data yang digunakan dalam penelitian ini ada tiga macam, yaitu metode observasi, dokumentasi dan wawancara. Instrumen pengumpulan data menggunakan lembar observasi dan daftar cocok dokumentasi. Teknik analisis data yang digunakan dalam penelitian ini adalah rating scale. Hasil penelitian menunjukkan bahwa tingkat ketercapaian kelengkapan peralatan praktik teknik Instalasi Tenaga Listrik di SMK Taruna Bangsa Bekasi pada tahun ajaran 2018/2019 dikategorikan sangat lengkap dengan persentase 89,36\%. Kelengkapan di tinjau dari perabotan ruang praktik yaitu $88.5 \%$ (sangat lengkap), media pembelajaran ruang praktik $100 \%$ (sangat lengkap), peralatan utama praktik 93\% (sangat lengkap), bahan utama ruang praktik 88.2\% (sangat lengkap) dan peralatan pendukung ruang praktik $77.1 \%$ (lengkap).
\end{abstract}

Kata kunci : Evaluasi, Peralatan praktik, Kelengkapan, Teknik Instalasi Tenaga Listrik

\section{PENDAHULUAN}

Pendidikan menurut Undang-undang Nomor 2/1989 tentang Sistem Pendidikan Nasional pasal 1 merupakan usaha sadar dan terencana untuk mewujudkaan suasana belajar dan proses pembelajaran agar peserta didik secara aktif mengembangkan potensi dirinya untuk memiliki kekuatan spiritual keagamaan, pengendalian diri, kepribadian, kecerdasan, akhlak mulia, serta ketrampilan yang diperlukan dirinya.Untuk memenuhi kebutuhan akan pen didikan tersebut manusia memasuki dunia pendidikan melalui proses belajar, dalam 
proses tersebut muncul pengaruh yang dapat membawa perubahan sikap atas manusia yang dipengaruhinya. Seiring dengan pengembangan ilmu pengetahuan dan teknologi menurut setiap orang untuk membekali dirinya lebih baik sehingga mampu membekali diri dengan perkembangan yang $\operatorname{ada}^{[1]}$. Salah satu untuk membekali diri adalah pendidikan, baik formal maupun non formal dan kompetensi yang dimiliki juga harus sesuai dengan standar pendidikan yang ada.

Proses belajar mengajar (PBM) di bengkel instalasi tenaga listrik meliputi kegiatan pengarahan teori sebagai landasan sebelum melakukan kegiatan praktek kemudian dilanjutkan dengan kegiatan praktikum dengan obyek langsung yang pastinya membutuhkan berbagai perlengkapan yaitu fasilitas sarana praktik. Fasilitas praktik dalam pendidikan kejuruan sangat berpengaruh terhadap kualitas pelajaran praktik. Praktik memerlukan media atau fasilitas yang cukup untuk menumbuhkan keterampilan. Sebagai bengkel instalasi tenaga listrik yang layak harus memiliki fasilitas praktik yang sesuai standar yaitu Permendiknas No. 1 tahun 2019 ${ }^{[2]}$ dan Badan Standar Nasional Pendidikan No. 1103-P2-18/19 mengenai Instrumen Verifikasi SMK Tentang Penyelenggara Ujian Praktik Kejuruan Tahun 2018/2019. ${ }^{\text {[3] }}$

Berdasarkan wawancara dan survei bengkel Instalasi Tenaga listrik di SMK Taruna Bangsa Bekasi digunakan untuk enam kelas terdiri kelas kelas sepuluh, sebelas dan dua belas. Bengkel listriks digunakan secara bergilir sesuai jadwal yang ditentukan sekolah. Jadwal pemakaian yang padat mengakibatkan umur pakai peralatan pendidikan di bengkel listrik semakin pendek. Umur pakai yang semakin pendek maka akan mengurangi jumlah peralatan yang ada karena rusak.

\section{METODE PENELITIAN}

Metode penelitian ini menggunakan deskriptif kuantitatif. Metode penelitian deskriptif adalah metode penelitian yang berusaha menggambarkan dan menginterprestasi objek sesuai dengan apa adanya. Model evaluasi yang dipilih menggunakan discrepancy.

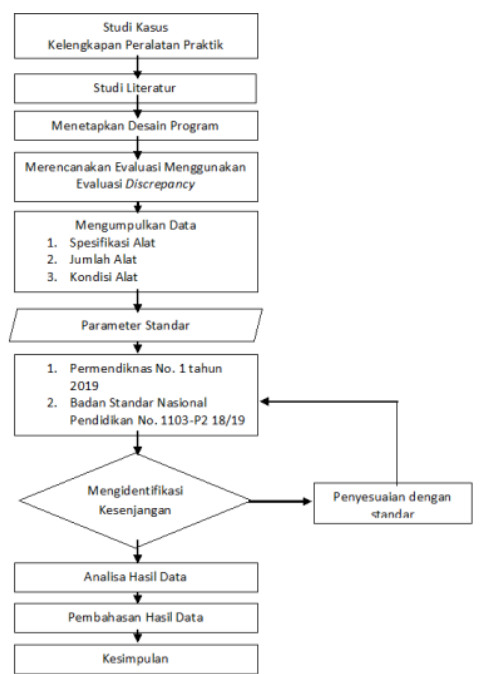

Gambar 1. Desain Penelitian

\section{Teknik Pengumpulan Data}

Teknik pengumpulan data yang digunakan dalam penelitian ini adalah metode observasi menggunakan daftar checklist peralatan, dokumentasi untuk menjaring data yang berkenaan dengan kondisi bengkel listrik, data inventaris peralatan dan wawancara pengumpulan data ini digunakan untuk menjaring data tentang kondisi bengkel listrik, peralatan di bengkel listrik serta spesifikasi peralatan.

\section{Teknik Analisis Data}

Dalam penelitian evaluasi, teknik analisis data yang digunakan yaitu dengan statistik. Statistik yang digunakan dalam penelitian ini adalah statistik deskriptif, yaitu statistik yang digunakan untuk menganalisa data dengan cara mendeskripsikan atau menggambarkan data yang telah terkumpul sebagaimana adanya tanpa bermaksud membuat kesimpulan yang berlaku untuk umum atau generalisasi ${ }^{[5]}$. Jadi, dalam statistik deskriptif tidak ada uji signifikansi dan taraf kesalahan, karena penelitian ini tidak bermaksud untuk membuat kesimpulan untuk umum atau generalisasi. Kemudian bedasarkan standar evaluasi Badan Nasional Standar Pendidikan (BNSP) kelengkapan harus memenuhi tiga hal yaitu spesifikasi alat, jumlah alat, dan kondisi alat. Dengan demikian ada tiga faktor penilaian maka dapat dirumuskan sebagai berikut ${ }^{[6]}$.

Keterangan :

$$
A=\frac{A 1+A 2+A 3}{n \times 3} \times 100 \%
$$

A $=$ Skor kelengkapan 
nx3 = Jumlah objek penilaian dikalikan 3

A1 $=$ Spesifikasi alat $(0-3)$

A2 = Jumlah alat $(0-3)$

A3 = Kondisi alat $(0-3)$

Pada setiap faktor penilaian memiliki aspek skor sendiri sesuai dengan perumusan masingmasing factor yang dijabarkan sebagai berikut :

\section{Spesifikasi Alat}

Tabel 1. Kriteria Pensekoran Peringkat

\begin{tabular}{cc}
\multicolumn{2}{c}{ Spesifikasi Alat } \\
\hline Peringkat & Skor \\
\hline Sama dengan standar & 3 \\
Dibawah & 2 \\
standar/mendekati & \\
Tidak sesuai standar & 1 \\
Tidak ada & 0 \\
\hline
\end{tabular}

\section{Jumlah Alat}

Analisis jumlah alat/kelengkapan menggunakan Skala Persentase dilakukan dengan cara mengkalikan hasil bagi skor riil dengan skor ideal dengan seratus persen ${ }^{[7]}$.

$$
\text { Pencapaian }=\frac{\text { skor riil }}{\text { skor ideal }} \times 100 \%
$$

Tabel 2. Kriteria Pensekoran Peringkat

\begin{tabular}{ccc} 
& Kelengkapan Alat \\
\hline Peringkat & Persentase & Sk \\
& Skor & or \\
\hline Sangat & $>66,6-$ & 3 \\
lengkap & $100 \%$ & \\
Lengkap & $>33,3-$ & 2 \\
& $66,6 \%$ & \\
Kurang & $>0-33,3 \%$ & 1 \\
lengkap & & \\
Tidak ada & $>0 \%$ & 0 \\
\hline
\end{tabular}

\section{Kondisi Alat}

Setiap alat memiliki kondisi tertentu untuk menuhi kebutuhan praktikum di sekolah maka dari itu perlu ditentukan kriteria penskoran yang cocok agar kondisi dapat dinilai sehingga dapat dievaluasi.

Tabel 3. Kriteria Pensekoran Peringkat Kondisi

\begin{tabular}{cc}
\multicolumn{2}{c}{ Alat } \\
\hline Peringkat & Skor \\
\hline Sangat layak & 3 \\
Layak & 2
\end{tabular}

\begin{tabular}{cc} 
Kurang layak & 1 \\
Tidak ada & 0 \\
\hline
\end{tabular}

\section{HASIL \& PEMBAHASAN \\ Perabotan Ruang Praktik}

Berikut adalah persentase kelengkapan perabotan ruang praktik

Tabel 4. Kelengkapan Perabotan Ruang Praktik

\begin{tabular}{cc}
\hline No. & Nama Alat \\
\hline 1 & Kursi kerja \\
2 & Meja kerja \\
3 & Bangku kerja \\
4 & Meja alat \\
5 & Meja Persiapan \\
6 & Stool/ Kursi kerja bengkel \\
7 & Papan tulis Dorong \\
8 & Lemari alat/ tools cabinet \\
9 & Lemari simpan \\
\hline Sub total skor A1 = 27 A2 $=23$ \\
A3 = 27
\end{tabular}

$$
\mathrm{A}=\frac{27+23+27}{27 \times 3} \times 100 \%=88.5 \%
$$

Berdasarkan tabel 1 dapat dilihat bahwa spesifikasi (A1) dengan skor 27, kelengkapan (A2) dengan skor 23, kondisi (A3) dengan skor 27. Sedangkan persentase skor kelengkapan (A) $88.5 \%$. ), perabotan ruang praktik dikategorikan sangat lengkap yang berada pada rentang 66,6 $\%-100 \%$.

\section{Media Pembelajaran Ruang Praktik}

Berikut adalah persentase kelengkapan Media Pembelajaran ruang praktik

Tabel 5. Kelengkapan Media Pembelajaran

\begin{tabular}{cc} 
& Ruang Praktik \\
\hline No. & Nama Alat \\
\hline 1 & Papan tulis \\
2 & Papan kerja/kemajuan \\
& siswa \\
3 & Wall chart \\
4 & LCD \\
\hline \multicolumn{2}{l}{ Sub total skor A1 $=12$ A2 $=12$}
\end{tabular}

A3 $=12$

$$
\mathrm{A}=\frac{12+12+12}{12 \times 3} \times 100 \%=100 \%
$$

Berdasarkan tabel 2 dapat dilihat bahwa spesifikasi (A1) dengan skor 12, kelengkapan (A2) dengan skor 12, kondisi (A3) dengan skor 
12. Sedangkan persentase skor kelengkapan (A) $100 \%$., media pembelajaran dikategorikan sangat lengkap yang berada pada rentang 66,6 $\%-100 \%$.

\section{Peralatan Utama Ruang Praktik}

Berikut adalah persentase kelengkapan peralatan utama ruang praktik

Tabel 6. Kelengkapan Peralatan Utama Praktik

\begin{tabular}{cc}
\hline No. & Nama Alat \\
\hline 1 & Emergency stop \\
2 & Lampu pilot/panel \\
3 & Magnetic Contactor \\
4 & MCB 1 Fasa \\
5 & MCB 3 Fasa \\
6 & Motor listrik 3 fasa 1 HP \\
7 & Panel box \\
8 & Push button switch \\
9 & Rel omega \\
10 & Thermal Overload Relay \\
11 & Time Delayed relay + base \\
12 & Terminal Strip \\
13 & ELCB \\
14 & Saklar seri \\
15 & Saklar tukar \\
16 & Fitting duduk \\
17 & Box MCB \\
18 & PLC \\
19 & Transformator \\
20 & Limit switch \\
21 & Elbow \\
22 & Stop kontak \\
\hline Sub total skor A1 = 63 A2 $=59$ \\
A3 63 & \\
\hline
\end{tabular}

$$
A=\frac{63+59+63}{66 \times 3} \times 100 \%=93 \%
$$

Berdasarkan tabel 3 dapat dilihat bahwa spesifikasi (A1) dengan skor 63, kelengkapan (A2) dengan skor 59, kondisi (A3) dengan skor 63. Sedangkan persentase skor kelengkapan (A) 93\%. ), nilai tersebut dikategorikan sangat lengkap yang berada pada rentang 66,6 \% - 100 $\%$.

\section{Peralatan Bahan Utama Ruang Praktik}

Berikut adalah persentase kelengkapan bahan utama ruang praktik

Tabel 7. Kelengkapan Bahan Utama Praktik

\begin{tabular}{|c|c|}
\hline No. & Nama Alat \\
\hline 1 & $\begin{array}{l}\text { Kabel NYAF } 1.5 \mathrm{~mm} \\
\text { Coklat }\end{array}$ \\
\hline 2 & $\begin{array}{l}\text { Kabel NYAF } 1.5 \mathrm{~mm} \\
\text { Merah }\end{array}$ \\
\hline 3 & $\begin{array}{l}\text { Kabel NYAF } 1.5 \mathrm{~mm} \\
\text { Kuning }\end{array}$ \\
\hline 4 & $\begin{array}{c}\text { Kabel NYAF } 1.5 \mathrm{~mm} \\
\text { Hitam }\end{array}$ \\
\hline 5 & Kabel NYAF $1.5 \mathrm{~mm}$ Biru \\
\hline 6 & Kabel NYM 4 x 1.5 mm2 \\
\hline 7 & Kabel Ties \\
\hline 8 & Kanal/duct kabel \\
\hline 9 & Klem kabel \\
\hline 10 & Paku skrup \\
\hline 11 & Pipa fleksibel \\
\hline 12 & Pipa PVC Clipsal \\
\hline No. & Nama Alat \\
\hline 13 & Sepatu kabel/skun 0.75 \\
\hline 14 & $\mathrm{~mm} 2$ \\
\hline 15 & Sepatu kabel/skun 1.5 \\
\hline 16 & $\mathrm{~mm} 2$ \\
\hline 17 & $\begin{array}{c}\text { Sepatu kabel/skun } 2.5 \\
\mathrm{~mm} 2\end{array}$ \\
\hline & $\begin{array}{l}\text { Spiral wrapping band } \\
\text { Terminal sambung }\end{array}$ \\
\hline \multicolumn{2}{|c|}{$\begin{array}{l}\text { Sub total skor A1 }=51 \text { A2 }=36 \\
\text { A } 3=45\end{array}$} \\
\hline
\end{tabular}

$$
\mathrm{A}=\frac{51+36+45}{51 \times 3} \times 100 \%=88.2 \%
$$

Berdasarkan tabel 1 dapat dilihat bahwa spesifikasi (A1) dengan skor 51, kelengkapan (A2) dengan skor 36, kondisi (A3) dengan skor 45. Sedangkan persentase skor kelengkapan (A) $88.2 \%$. ), nilai tersebut dikategorikan sangat lengkap yang berada pada rentang 66,6 \% - 100 $\%$.

\section{Peralatan Pendukung Ruang Praktik}

Berikut adalah persentase kelengkapan peralatan pendukung ruang praktik

Tabel 8. Kelengkapan Pendukung Ruang Praktik

\begin{tabular}{cc}
\hline No. & Nama Alat \\
\hline 1 & Tang kombinasi \\
2 & Tang pemotong \\
3 & Tang pengupas kabel \\
4 & Tang lancip \\
5 & Obeng (+)
\end{tabular}




$\begin{array}{cc}6 & \text { Obeng (-) } \\ 7 & \text { Pisau cutter } \\ 8 & \text { Test pen } \\ 9 & \text { Crimping } \\ 10 & \text { Bor listrik } \\ 11 & \text { Multimeter / AVO meter } \\ 12 & \text { Tang Ampere } \\ 13 & \text { Megger } \\ 14 & \text { Gergaji } \\ 15 & \text { Palu besi } \\ 16 & \text { Freet bor jara } \\ 17 & \text { Meteran }\end{array}$

Sub total skor $\mathrm{A} 1=45 \mathrm{~A} 2=28 \mathrm{~A} 3=45$

$$
\mathrm{A}=\frac{45+28+45}{51 \times 3} \times 100 \%=77.1 \%
$$

Berdasarkan tabel 1 dapat dilihat bahwa spesifikasi (A1) dengan skor 45, kelengkapan (A2) dengan skor 28, kondisi (A3) dengan skor 45. Sedangkan persentase skor kelengkapan (A) $77.1 \%$. ), nilai tersebut dikategorikan sangat lengkap yang berada pada rentang 66,6 \% - 100 $\%$.

\section{KESIMPULAN DAN SARAN \\ Kesipulan}

Berdasarkan hasil penelitian dan pembahasan di atas maka simpulan yang diperoleh dalam penelitian ini adalah:

1. Kelengkapan peralatan praktik Teknik Instalasi Tanaga Listrik di SMK Taruna Bangsa Bekasi pada tahun ajaran 2018/2019 termasuk dalam kategori sangat lengkap dengan persentase $89,36 \%$.

2. Kelengkapan peralatan praktik Teknik Instalasi Tanaga Listrik di SMK Taruna Bangsa Bekasi pada tahun ajaran 2018/2019 terdiri dari 5 jenis objek yaitu $88.5 \%$ (sangat lengkap), aspek yang lain yaitu media pembelajaran ruang praktik $100 \%$ (sangat lengkap), peralatan utama praktik yaitu 93\% (sangat lengkap), bahan utama ruang praktik $88.2 \%$ (sangat lengkap) dan persentase pencapaian kelayakan terendah adalah peralatan pendukung ruang praktik yang $77.1 \%$ (sangat lengkap).

\section{Saran}

1. Bagi sekolah, untuk menyediakan jumlah peralatan minimal standar yang masih kurang yang ditentukan dalam peraturan antara lain motor listrik, tang ampere, sehingga dapat mencukupi kebutuhan siswa mengenai peralatan praktik.

2. Pihak sekolah tidak hanya memenuhi kelengkapan alat namun juga kelayakannya sehingga sesuai standar.

\section{DAFTAR PUSTAKA}

[1]Undang-undang No. 2. (1989). Sistem Pendidikan Nasional. Jakarta : Sikdiknas.

[2]Peraturan Menteri Pendidikan dan Kebudayaan Republik Indonesia Nomor 1. (2019). Tentang Petunjuk Operasional Dana Alokasi Khusus Fisik Bidang Pendidikan.

[3]Badan Standar Nasional Pendidikan (BSNP). Instrumen Verifikasi SMK Tentang Penyelenggara Ujian Praktik Kejuruan, Instrumen Verifikasi SMK Tentang Penyelenggara Ujian Praktik Kejuruan (2019). DKI Jakarta, Jakarta Barat.

[4]Sugiyono. (2010). Metodelogi Penelitian Kuantitatif, Kualitatif Dan R\&D. Bandung: Alfabeta.

[5]Sugiyono. (2010). Metodelogi Penelitian Kuantitatif, Kualitatif Dan R\&D. Bandung: Alfabeta.

[6]Badan Standar Nasional Pendidikan (BSNP). Instrumen Verifikasi SMK Tentang Penyelenggara Ujian Praktik Kejuruan, Instrumen Verifikasi SMK Tentang Penyelenggara Ujian Praktik Kejuruan (2019). DKI Jakarta, Jakarta Barat

[7]Sugiyono. (2010). Metodelogi Penelitian Kuantitatif, Kualitatif Dan R\&D. Bandung: Alfabeta. 